\title{
midiäticale
}

\section{A construção da imagem da Igreja Católica em postagens online}

The construction of the image of the Catholic Church in posts online

\author{
Adriano Charles Silva CRUZ ${ }^{1}$ \\ Rossano José Batista CABRAL JÚNIOR ${ }^{2}$
}

\section{Resumo}

Este trabalho analisa as imagens e discursos da Igreja Católica durante a Jornada Mundial da Juventude do Rio de Janeiro, em 2013, na fanpage oficial. Vivia-se um momento de uma nova gestão eclesial, com a eleição do Papa Francisco. Além disso, o evento foi intensamente mediado pela imprensa e pelas redes sociais. Elegemos as imagens presentes na rede social mais utilizada no Brasil naquele ano. A partir de uma perspectiva discursiva, analisamos a construção da imagem institucional. $\mathrm{O}$ estudo identificou a ocorrência dos discursos de renovação e de sedução, a partir dos usos da memória e da figura do Papa.

Palavras-chave: Imagem institucional. Redes sociais. Análise de discurso. Midiatização.

\begin{abstract}
This work analyzes the images and speeches of the Catholic Church during the World Youth Day in Rio de Janeiro, in 2013, in the official fanpage. There was a moment of new management in the church, with the election of Pope Francis. In addition, the event was intensively mediated by the press and by social networks. We chose the images on the most used social network in Brazil that year. From a discursive perspective, we analyze the construction of the institutional image. The study identified the occurrence of discourses of renewal and seduction, from the uses of memory and the figure of the Pope.
\end{abstract}

Keywords: Institutional image. Social networks. Discourse analysis. Mediatization.

\footnotetext{
1 Pós-doutorando em Comunicação pela Escola de Comunicação e Artes de São Paulo (ECA/USP). Professor do Departamento de Comunicação Social da UFRN. Coordena o Grupo de Pesquisa CiCultCírculo de Cultura Visual (UFRN/CNPq). E-mail: adrianocruzufrn@gmail.com

${ }^{2}$ Mestrando em Gestão Institucional. Pesquisador do CiCult-Círculo de Cultura Visual (UFRN).
E-mail: rossanojr@gmail.com
} 


\section{midiática@ę)}

\section{Introdução}

As estruturas discursivas da propaganda institucional nas redes sociais digitais constroem representações de mundo marcadas pela persuasão. Essas estruturas se materializam em imagens e textos prenhes de simbolismo e historicidade. Os discursos publicitários, em sua maioria, objetivam promover uma imagem favorável às organizações. É, portanto, indispensável se pensar na articulação das imagens e sua circulação contemporânea na hegemonia das mídias sociais e na interatividade do mundo online.

Nesse tempo de conexão e alta interatividade, os receptores são também produtores de imagens e discursos nas redes sociais. A própria sociedade se transformou a partir da lógica da midiatização que atravessa todas as práticas sociais. É por meio da mediação das mídias e de outras tecnologias que nos identificamos como sujeitos no mundo e construímos nossa experiência de estar no mundo.

Nesta investigação, analisamos como se construiu a propaganda da Igreja Católica no Facebook durante a Jornada Mundial da Juventude (JMJ) ${ }^{3}$ de 2013, primeiro ano de pontificado do argentino Jorge Mario Bergoglio. O objetivo geral é analisar o discurso institucional nas postagens oficiais da fanpage (@jornadamundialdajuventude) no período em tela.

Defendemos a hipótese de que esse evento consolidou uma mudança na imagem da Igreja Católica, que já começava a se desenhar graças à transição dos pontificados do Papa Bento XVI para o Papa Francisco.

A partir de Prado (2013), entendemos que a imagem institucional é constituída pelo conjunto de significados que remetem a uma determinada organização, ou seja, como ela é pela opinião pública. Esse conjunto de imagens é dinâmico, mas tende a se consolidar em uma "reputação", ao longo dos anos, graças às ações, discursos, estratégias e resultados de uma instituição.

Em 2013, o Brasil tinha 76 milhões de usuários do Facebook, dos quais 47 milhões acessavam-no diariamente, o que nos colocava em segundo lugar nessa

\footnotetext{
${ }^{3}$ As jornadas são eventos oficiais que ocorrem a cada dois anos em uma cidade do mundo escolhida como sede. Começou em 1986 e reúne jovens, padres, bispos e o Papa.
} 


\section{midiäticales}

categoria, conforme matéria publicada no portal de notícias $\mathrm{G} 1^{4}$. Além disso, essa rede se configurava como uma mídia promotora de novas formas de sociabilidade e de intensa troca de informações e circulação de posições discursivas distintas. No caso específico da JMJ, o Facebook foi uma das ferramentas mais usadas para as postagens propagandísticas, o que o justifica como locus privilegiado de investigação.

O contexto que leva o Papa Bento XVI à renúncia, em 28 de fevereiro de 2013, promoveu inquietação em muitos cristãos católicos, posto que fora o primeiro caso na história recente. A crise gerada pela renúncia do pontífice, associada ao desgaste da imagem eclesial, em decorrência dos escândalos de corrupção, de abuso de poder, de omissão em casos de pedofilia cometidos por presbíteros católicos e dos conflitos com "os mundos" islâmico e hebreu, promoveu a emergência de discursos contrários às estruturas hierárquicas.

A mudança do pontificado para o argentino Francisco promove uma mudança em direção a um ideal franciscano de simplicidade. Além disso, uma série de fatores históricos contribui para a construção dessa novidade: Francisco, eleito em 13 de março de 2013, é o primeiro Papa latino-americano e jesuíta. E, desde 1415, não havia uma renúncia papal. Tais acontecimentos históricos, aliados às características pessoais do jesuíta, atraíram a atenção dos jornalistas de todo o mundo.

De fato, a eleição de Francisco e as posteriores mudanças progressistas promoveram um ambiente favorável à atração dos jovens católicos. Em novembro de 2013, uma matéria do jornal The Times aponta um crescimento do número de pessoas que se auto definiam como católicas no EUA, na França e na América Latina. "Os resultados sugerem que o apelo 'eletrizante' de Francisco está dando nova vida a uma igreja fustigada pelos escândalos em série de padre pedófilos" (THE TIMES, 2018, tradução nossa) $)^{5}$. Assim, acreditamos que "novos ares" sopram na Igreja do carismático Francisco, logo, uma oportunidade se desenhava para um reposicionamento da imagem institucional, como na Jornada. Tal pressuposto é também defendido por Almeida (2013, p. 298): “a visita do Papa Francisco ao Brasil no mês de julho foi um evento

\footnotetext{
4 "Brasil é o $2^{\circ}$ país com mais usuários que entram diariamente no Facebook. Em número total de usuários, no entanto, país fica em $3^{\circ}$, atrás da Índia". Disponível em: <http://g1.globo.com/tecnologia/noticia/2013/09/brasil-e-o-2-pais-com-mais-usuarios-que-entramdiariamente-no-facebook.html>. Acesso em: 10 out. 2015.

${ }^{5}$ Disponível em: <https://www.thetimes.co.uk/article/francis-effect-pulls-crowds-back-to-churchsb5stbzmzgt $>$. Acesso em: 15 de out 2015.
}

Ano XI, n. 21 - jul-dez/2018 - ISSN 1983-5930 - http://periodicos.ufpb.br/ojs2/index.php/cm 


\section{midiäticale}

midiático não apenas por estar associado à JMJ, mas também pelo conteúdo de seu discurso e pelas sinalizações de sua performance pessoal”.

Embora se tenha toda uma estrutura milenar, a figura papal se destaca; muitas vezes, sua personalidade e ações se sobrepõem à instituição Igreja. Em 2013, lançou-se o aplicativo The Pope App, que segue os passos do Papa Francisco por meio de vídeos ao vivo, fotos, reportagens e textos sobre o religioso. O Papa e os seus social media também interagem frequentemente com as pessoas nas redes sociais digitais, por meio de contas pessoais no Instagram e no Twitter, em vários idiomas.

As redes sociais têm se popularizado com facilidade impressionante, atingindo cerca de 1,3 bilhão de pessoas em 2014, segundo dados de matéria assinada por Ravi Somaiya, publicada no New York Times. Foi nesse boom das redes sociais que se inseriram as postagens do Facebook que analisamos neste artigo.

O recorte do corpus engloba as postagens de imagem destacadas pelo perfil oficial da JMJ nos períodos de 23 a 28 de julho de 2013, semana em que ocorreu na cidade do Rio de Janeiro o evento que reuniu milhões de pessoas de todo o mundo. $\mathrm{O}$ período de observação, coleta e sistematização do corpus a ser analisado se deu entre os dias 01 e 08 de outubro de 2015. Pelas limitações inerentes, serão desconsiderados os comentários de terceiros, bem como o texto auxiliar das postagens. Ou seja, servirá para esta análise discursiva apenas o material disponível no "quadro" da postagem.

Nas imagens sincréticas, textos, gestos, cores e enquadramentos se reúnem para construir sentidos que mobilizam a participação e a integração da juventude à Igreja. Os gestos interpretativos que lançamos a esses posts nos permitem entender os deslocamentos discursivos e a sedução desses textos na fronteira da linguagem publicitária e informativa.

Após a revisão de literatura, desenvolvemos uma análise que tem como fundamentação teórico-metodológica a $\mathrm{AD}$ de linha francesa a partir dos autores Courtine (2008), Pêcheux (1997), Orlandi (2007) e Cruz (2014). Para tanto, a fim de dar conta de nossos objetivos, mobilizamos os conceitos de ideologia, interdiscurso, memória discursiva e intericonicidade. 


\section{midiática@ę)}

As redes sociais e as dinâmicas da interação

Nos últimos anos, testemunhamos a convergência entre as mídias por meio de conteúdos que interagem entre uma plataforma e outra. Jenkins (2009, p. 29) nos ajuda a entender esse universo quando explica que a convergência se deve "[...] ao fluxo de conteúdos através de múltiplas plataformas de mídia, à cooperação entre múltiplos mercados midiáticos e ao comportamento migratório dos públicos dos meios de comunicação".

Ainda hoje a internet tem muito a se descobrir e cada vez mais tem auxiliado a rotina do ser humano. Segundo Briggs e Burke (2006, p. 309), “com a chegada da internet, aumentaram as possibilidades de aprendizado continuado, formal e informalmente, sempre que a experiência ou a expectativa requisitassem”. É por causa disso que os usuários têm buscado cada vez mais conteúdo em lugares ainda mais distintos, visando se informar acerca de algo. Não é diferente entre os usuários católicos. Hoje, muitas são as alternativas de acesso a conteúdo cristão online. Livros podem ser comprados ou adquiridos gratuitamente; músicas e filmes baixados em aplicativos ou streaming, da mesma forma; emissoras de TV têm se preocupado com a adaptação de seus formatos para a web, como acontece com as emissoras católicas Canção Nova e Rede Vida. Há ainda uma série de serviços religiosos online como orações, aconselhamento e discussões em redes; pedidos de oração em sites específicos e capelas virtuais, entre outras formas de culto.

A Igreja Romana já há alguns anos intensificou sua presença no mundo online. Em 2009, o Vaticano lança um canal no YouTube. No ano seguinte, lança o portal New.va. Em 2012, a Rádio Vaticana passa a transmitir quase exclusivamente pela internet. Em uma sociedade marcada pela espetacularização, a vida dos sujeitos famosos é cercada pelo interesse social e pela mediação midiática.

Com as mídias digitais, plataformas eletrônicas as quais permitem acesso à internet e, por conseguinte, a interação entre usuários, é normal perceber o quanto os papéis de emissor e receptor se hibridizam, fazendo com que a comunicação percorra um caminho em espiral: "Usuários e criadores podem tornar-se a mesma coisa. Dessa forma, os usuários podem assumir o controle da tecnologia, como já acontece no caso 


\section{midiäticaef \\ REVISTA DO PROGRAMADE

da internet" (CASTELLS, 1999, p. 57). É a era dos blogueiros, youtubers e vloggers, que com um smartphone produzem conteúdo, arrastam seguidores e engajamento e, alguns, se tornam milionários. Até a produção de notícias, antes exclusiva dos jornalistas, passa a ser realizada pelos novos experts das redes sociais. A Igreja, por sua vez, viu nessas mídias digitais o caminho adequado para atingir os jovens de todo o mundo.

Na segunda década do século XXI, a internet tem estado mais próxima dos hábitos humanos, seja numa SmartTV, seja num Smartphone, que, há certo tempo, deixaram de ser sinônimo apenas para telecomunicações. É possível percebermos outros utensílios, que, no século passado, jamais se pensaria que teriam conexão com a web, como é o caso de alguns tipos de relógios, óculos, tablets, entre outros, além do acesso quase contínuo às redes sociais.

Segundo Kartajaya, Kotler e Setiawan (2010), as redes sociais auxiliam a construir o novo perfil do consumidor da informação. Por elas, os indivíduos estão conectados uns aos outros, compartilhando informações e experiências diversas que possibilitam a tomada de atitude mais consciente, bem fundamentadas no testemunho do outro.

A Igreja Católica, vista como instituição mundialmente reconhecida, tem estado mais presente nas mídias sociais. O Papa, para se manter mais próximo a suas “ovelhas”, criou uma conta do Twitter e lá posta conteúdos, normalmente relacionados ao Evangelho.

Até o momento de escrita deste texto, a JMJ mantém uma página oficial na rede social Facebook, por meio da qual oferece informações sobre os próximos eventos, bem como recortes das edições passadas do evento. Isso gera mídia espontânea entre aquelas pessoas que estiveram nas edições ocorridas ou pretendem ir às próximas. A interatividade tem trazido para a Igreja essa nova dimensão social, pela qual instituição e indivíduo “[...] compartilham conjuntos semelhantes de valores e desejos" (KARTAJAYA; KOTLER; SETIAWAN, 2010, p. 12).

A Igreja tem se voltado às redes sociais e ampliado o relacionamento com fiéis, sobretudo com os jovens. Esses, por sua vez, se preocupam em interagir, reafirmar ou, até mesmo, ressignificar as mensagens católicas, de maneira a contribuir com os objetivos da Igreja. Um exemplo desse engajamento são os youtubers católicos que 


\section{midiäticale}

produzem conteúdo com uma linguagem despojada, humorística e coloquial, além de uma técnica despojada de captação e edição de imagens ${ }^{6}$.

Todavia, não é possível excluir os veículos tradicionais que têm um papel de respaldar a opinião pública, posto que ainda gozam de credibilidade. Durante a JMJ, destacaram-se a Rede Globo de TV e a GloboNews, que cobriram a jornada em todos os telejornais e transmitiram as últimas missas na íntegra. Essa visão tão positiva leva Almeida (2013, p. 300) a questionar a neutralidade jornalística. "A cobertura revelou ainda que alguns dos jornalistas globais podem também ser considerados quadros da Igreja Católica na cena pública ou no mínimo estão em sintonia com ela". O que mostra a "mudança de ventos" do Papa Francisco e a construção de uma imagem institucional favorável.

\section{Memória, discurso e significações}

Todos os elementos visuais e textuais são importantes na mensagem persuasiva da propaganda. Os verbos, os adjetivos, os sinônimos, os artigos e a combinação das palavras produzem significações variadas a partir de quem escreve, a partir de quais objetivos e em que momento sócio-histórico. De maneira análoga, o enquadramento, as cores, o jogo de luz e sombra, a existência ou não de personagens são elementos preciosos para se investigar os efeitos produzidos pelas práticas discursivas.

Em princípio, faz-se necessário entendermos o que denominamos como discurso. Como ponto de partida, não podemos restringir o discurso a somente uma troca de informações ou a uma enunciação, ele possui uma dimensão não somente linguística, mas ideológica, brota do cruzamento entre "história, sujeito e ideologia", pois todo o discurso é social. Dessa forma, "ele estará, necessariamente, influenciado pelas condições sócio-históricas que lhe deram origem" (CRUZ, 2014, p. 31).

É nesse encontro entre um sujeito historicamente situado e a sua formação ideológica que são gerados os efeitos de sentido; logo, o discurso é algo dinâmico, devemos observar as suas relações com a história e com a sociedade. Por exemplo, é à luz da crise da Igreja e de uma intensa "midiatização da cultura e da sociedade" (HJARVARD, 2014) que interpretamos o discurso de "novidade" sobre o Papa

\footnotetext{
${ }^{6}$ Entre esses, destacamos: Canal do Kevin, Bora Partilhar, Cristocêntrico e Exalando Santidade.
} 


\section{midiäticale}

Francisco, eleito pela revista Time como a "personalidade do ano" em novembro de 2013.

Em outras palavras, as significações são produzidas segundo a formação ideológica do sujeito. A partir dessa perspectiva, advogamos que ideologia não opera no mundo como um espectro, mas de maneira concreta nos sujeitos em sua relação com o mundo (CRUZ, 2014). Em outras palavras, a ideologia se materializa para os homens por meio das práticas humanas; está entre o sujeito e as atitudes deste. A representação de mundo ideológica é para Althusser (1970, p. 90) uma representação de mundo determinada pelas condições de existência. Essa "relação imaginária é em si mesma dotada de uma existência material".

Defendemos o papel coesivo da ideologia na sociedade e sua maneira de naturalizar os processos discursivos. A ideologia e o inconsciente se inter-relacionam e marcam a subjetividade: o sujeito "vivencia sua própria identidade como se ela estivesse reunida e 'resolvida', unificada, como resultado da fantasia de si mesmo como uma pessoa que ele formou na fase do espelho" (HALL, 2014, p. 42).

A ideologia se materializa nas marcas do texto a partir de suas condições de produção. Os sujeitos assumem posicionamentos discursivos distintos; logo, é por intermédio das formações discursivas que a ideologia se faz presente nas materialidades visuais e linguísticas. As palavras e as imagens significam a partir das formações ideológicas que estão submetidas. Por exemplo, as cores nacionalistas (verde e amarelo) funcionam como marca identitária de nacionalismo nos jogos da Copa do Mundo e na JMJ. Mas também podem se contrapor ao vermelho, utilizado por partidos e movimentos de esquerda, em manifestações de rua, por sujeitos que ideologicamente se opõem àqueles. O que muda é o quadro histórico e o posicionamento ideológico dos sujeitos envolvidos.

O interdiscurso, por sua vez, diz respeito ao movimento da memória e à retomada de discursos já proferidos. Segundo Orlandi (2007, p. 31), é lido como sinônimo de memória discursiva e corresponde ao "[...] saber discursivo que torna possível todo dizer e que retorna sob forma de pré-construído, o já dito que está na base do dizível, sustentando cada tomada da palavra". Em outras palavras, pode-se dizer que o interdiscurso é um princípio constitutivo da linguagem, marcado pela presença da 


\section{midiäticaef \\ REVISTA DO PROGRAMA DE \\ PÓS-GRADUACCÃO EM COMUNICACÃO DA \\ UNIVERSIDADE FEDERAL DA PARAIBAA}

"alteridade", já que não existe discurso adâmico, sem a força da história. Assim, todo discurso retoma, refuta, rememora, contradita ou silencia outros discursos “já ditos”.

Às vezes, é possível reconhecer a presença dessa interdiscursividade por meio de marcas materiais nos textos e imagens, tais como: citações, discurso direto, ironia, refutações, paródia, paráfrase, entre outros. E, graças ao movimento dessa "memória" que produzimos sentidos. Segundo Pêcheux (2007, p. 52), o interdiscurso ou memória discursiva: "[...] seria aquilo que, face a um texto que surge como acontecimento a ler, vem estabelecer os 'implícitos' [...] de que sua leitura necessita: a condição do legível em relação ao próprio legível”.

Exemplificando: à luz da história, a escolha do nome "Francisco" por Jorge Mario Bergoglio evoca efeitos interdiscursivos. O franciscano é sinônimo de simplicidade e amor aos mais simples. Daí que surge a expressão "pobreza franciscana", elogiada como sinal evangélico. A revista Veja, de 24 julho de 2013, retorna esse enunciado quando traz a manchete: "O Papa dos Pobres" e a imagem de Francisco.

Figura 1 - Mosaico das capas das revistas Time (29/07/2013 e 23/11/2013) e Veja (24/07/ 2013)
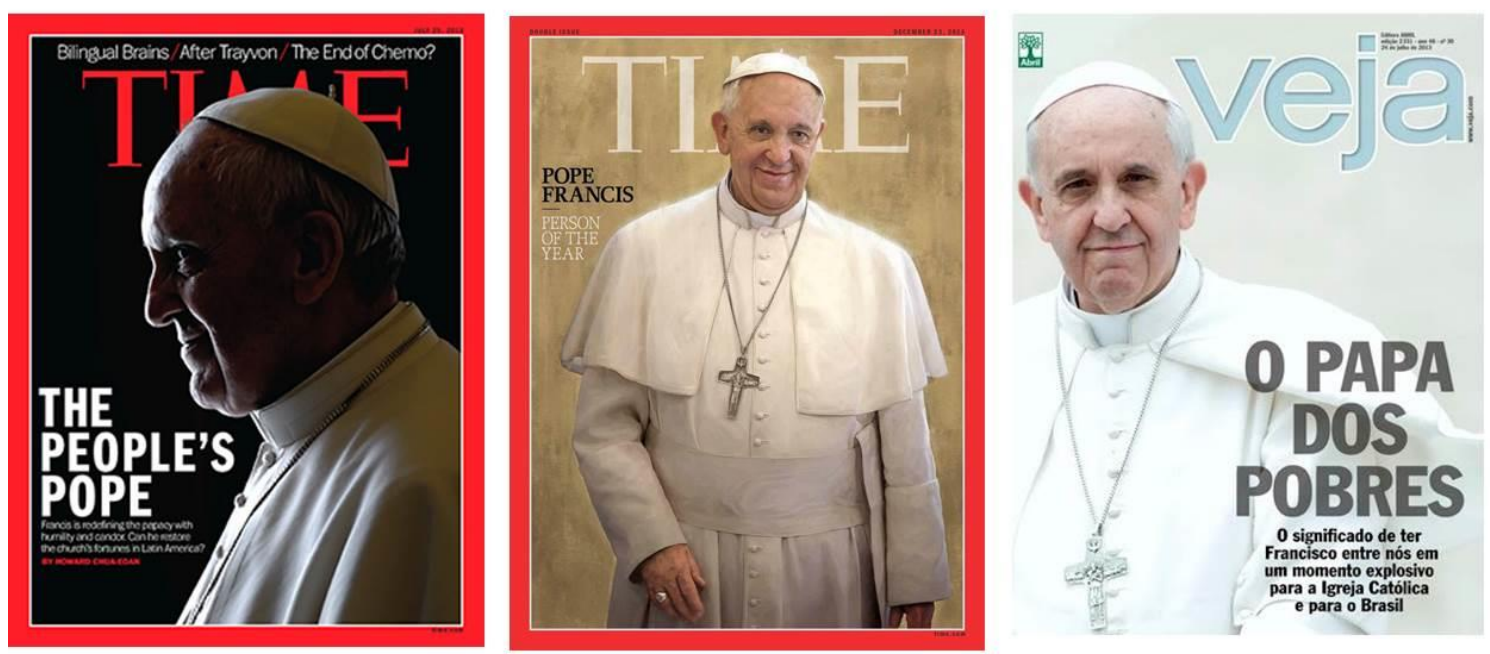

Fonte: Time e Veja

Courtine (2008, p. 17) se apropriou do conceito de memória para discutir a maneira como as imagens constroem sentidos. Essa intericonicidade seria "uma reflexão sobre a memória das imagens". Ou seja, a mesma dinâmica do movimento discursivo nos textos verbais ocorreria também nas imagens. Com isso o autor alarga as 


\section{midiäticale}

possibilidades de análise ao discutir como se produz um "rastro" de outras imagens e de discursos anteriores.

Por conseguinte, o sentido de uma imagem não depende apenas de seus elementos gráfico-pictóricos, mas dessas combinações internas com referências a outras imagens dentro de uma cultura de visualidade cada vez mais complexa. Assim, conforme Cruz (2014), o conceito de interdiscurso é válido tanto para as imagens quanto para os textos.

A análise de discurso que empregamos procurou identificar os movimentos da memória nos materiais postados pela fanpage da Jornada Mundial da Juventude na semana de 23 a 28 de julho de 2013. Demonstraremos, em seguida, os efeitos de sentido produzidos a partir da escolha dos elementos verbo-imagéticos e das relações interdiscursivas e intericônicas.

\section{Análise das postagens}

As duas imagens convidam o leitor a observar uma cena íntima, dois momentos em que se observam detalhes da presença do religioso no Brasil.

Desde a posse de Francisco, os meios de comunicação têm construído uma imagem de um líder carismático, acolhedor e próximo aos fiéis. De fato, conforme a narrativa jornalística, ele parece estar mais próximo ao povo, como indicam algumas ações pastorais: telefona para populares para prestar solidariedade ${ }^{7}$ ou parabenizar por natalícios e almoça com trabalhadores do Vaticano ${ }^{8}$ ou com mendigos. Tudo isso sendo registrado em imagens por assessores de imprensa e divulgado por agências internacionais como a Reuters.

\footnotetext{
${ }^{7}$ Cf. O Estado de São Paulo, 2018.

${ }^{8}$ Cf. Gl, 2018.
} 


\section{midiăticae \\ REVISTA DO PROGRAMADE \\ PÓS-GRADUAÇÃO EM COMUNICAÇÃO DA \\ UNIVERSIDADE FEDERAL DA PARAIBAA}

Figuras 2 e 3 - Postagens dos dias 23 e 25 de julho de 2013

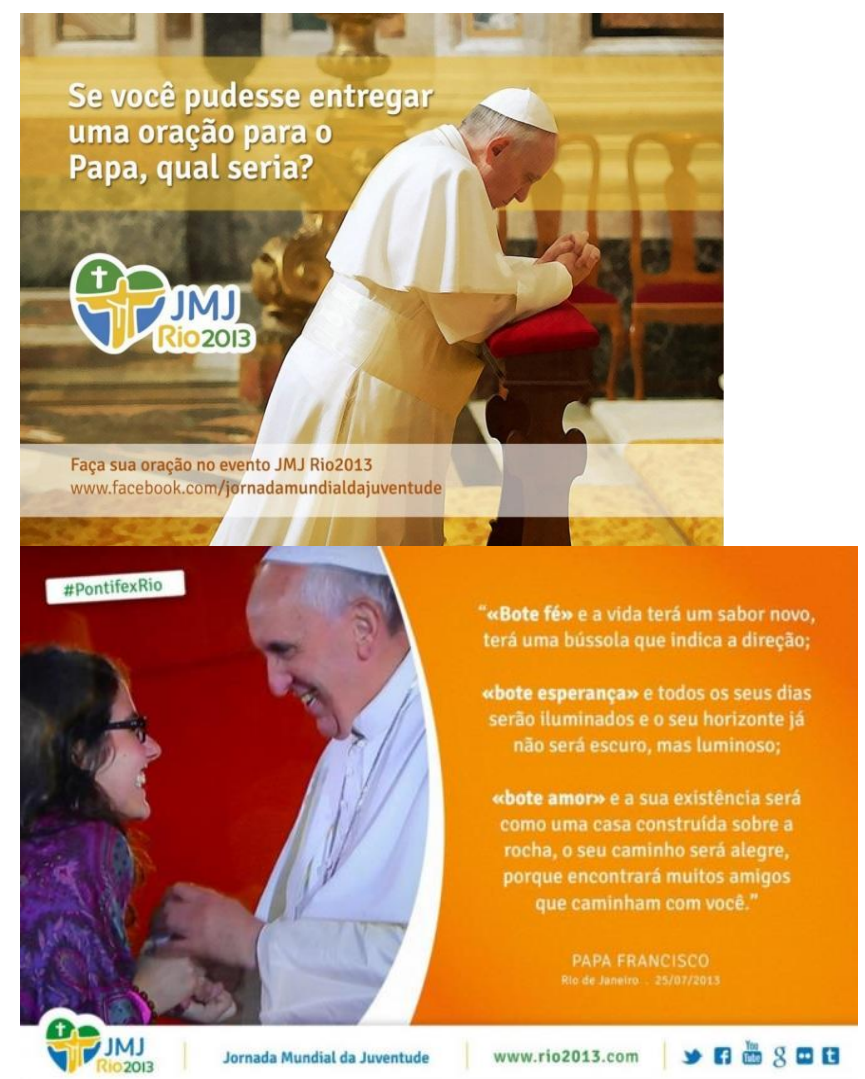

Fonte: facebook.com/jornadamundialdajuventude

A primeira postagem foi publicada no dia 23 de julho na fanpage da "Jornada Mundial da Juventude", a poucas horas do evento começar. É uma cena de expectativa, o Papa se recolhe em oração para se preparar para o evento. Eis a figura de um homem integrado com o divino, enuncia o post propagandístico.

É provável que o quadro seja uma imagem manipulada com o auxílio de softwares, para provocar uma estética específica: há aplicação de uma textura na foto que imita uma pintura. O ponto de vista do leitor é o voyeurista, que flagra uma cena de intimidade de um indivíduo famoso.

Por intermédio da memória, se identifica com o que se refere o gestual: trata-se de uma postura denominada "genuflexão". No paradigma católico, a postura denota subordinação a um ser superior (Deus); as mãos unidas configuram um sinal típico de "elo" (entre o céu e a Terra), por isso, é a posição do gesto da prece. Ao se deixar 


\section{midiäticale}

fotografar em um momento de "adoração" e ter essa imagem propagada, o Papa e sua equipe de comunicação fomentam a imagem de um sujeito piedoso e orante.

No enunciado verbal, percebemos um apelo à interação com os usuários da rede social. Essa interrogativa instiga no leitor o ato da participação. Em tela, o ideal de um líder acessível e capaz de suplicar por seus fiéis.

Segundo Farina (2000), o branco presente nas vestes representa a pureza, próprio de alguém digno de levar as preces a Deus. Por sua vez, o marrom, mesmo que em uma tonalidade mais diluída, faz referência a "roupas populares" (FARINA, 2000, p. 104). Logo, se reforça a discursivização de que a Igreja está mais próxima da realidade dos cristãos católicos. Intericonicamente, temos a imagem de alguém que é humilde e ama os pobres, já ecoados em outros lugares como no jornalismo. Em 29 de julho daquele ano, a revista Times já o tinha intitulado como "O Papa do povo".

No "rodapé" da imagem está presente a frase imperativa "Faça sua oração no evento JMJ Rio2013” e logo após é disponibilizado o endereço eletrônico da página oficial: “www.facebook.com/jornadamundialdajuventude". Mais uma vez, se convoca a interação dos usuários.

A assinatura com o endereço certamente está presente devido à possibilidade de compartilhamento da mensagem e a provável visualização por parte de alguém que não saiba de que se trata o evento. O selo da JMJ carrega ícones tipicamente brasileiros e as cores da bandeira do Brasil, retomando o efeito de sentido de nacionalismo.

Dois dias depois, temos outra imagem que também nos oferece adentrar em um momento íntimo, já que a edição e o enquadramento fotográfico permitem captar as expressões das personagens em tela.

Como quem aconselha, sorrindo, o Papa olha diretamente nos olhos da moça, que também sorri. Os dois tocam-se as mãos, em um gesto afetivo. Constrói-se uma discursivização de cumplicidade e intimidade entre os dois personagens que transborda para o leitor da imagem. É possível perceber a atmosfera de emoção imbricada no gesto deles, a aproximação proporcionada pelo plano fotográfico mais fechado torna o leitor partícipe do momento.

A presença da ideia de "renovação" se destaca no uso da metáfora "novo sabor" à vida proporcionada pela fé. O texto é um discurso direto e remete interdiscursivamente ao Evangelho (Mt 7, 24-27), à história de dois homens, um 


\section{midiäticale}

insensato e um prudente, cada um construiu uma casa: um sobre a areia e o outro sobre a rocha. No final, após as tempestades, só a do último prevaleceu. Assim, construir "a casa sobre o amor" é uma metáfora que indica continuidade, fortaleza e obediência à palavra divina.

Já a cor vermelha, presente no plano de fundo da imagem, intericonicamente,

remete ao amor fraternal (ágape) que o católico deveria vivenciar, conforme o conhecido mandamento bíblico de "amar o próximo".

A heterogeneidade discursiva se marca ainda pela presença da intertextualidade. Ocorreu, no Brasil, um evento preparatório à Jornada Mundial da Juventude, chamado de "Bote Fé". A estratégia de marketing e divulgação acontecia por meio da itinerância da "cruz peregrina", em algumas capitais do Brasil, acompanhada pela realização de shows de artistas católicos brasileiros consagrados para o público, incluindo os chamados "padres cantores". Tais eventos atraíram a atenção da juventude, produziam mídia espontânea em jornais, além de movimentar financeiramente as igrejas locais, com a venda de camisetas e de outros produtos.

As locuções "bote fé", "bote esperança" e "bote amor", em negrito, sintetizam os valores do cristianismo. Esses valores são tão importantes para a Igreja que são denominados de "virtudes teologais", oriundas da própria divindade, conforme advoga a catequese católica. Por intermédio do interdiscurso, o Papa utiliza o termo "bote", comum entre os jovens, para melhor se aproximar deles, retomando, assim, o enunciado anterior que circulava na memória discursiva. Torna-se importante ressaltar que diferente das outras postagens analisadas, nas figuras 4 e 5, o Papa fala diretamente ao público jovem. Tem-se o efeito de coloquialidade, de um líder que fala "a mesma língua", símbolo de juventude e da renovação. Nas próximas postagens, a corporeidade do Papa, em conjunção com os outros elementos, retoma essa ideia de juventude e coloquialidade. 


\section{midiătica@

Figuras 4 e 5 - Postagens do dia 26 de julho de 2013

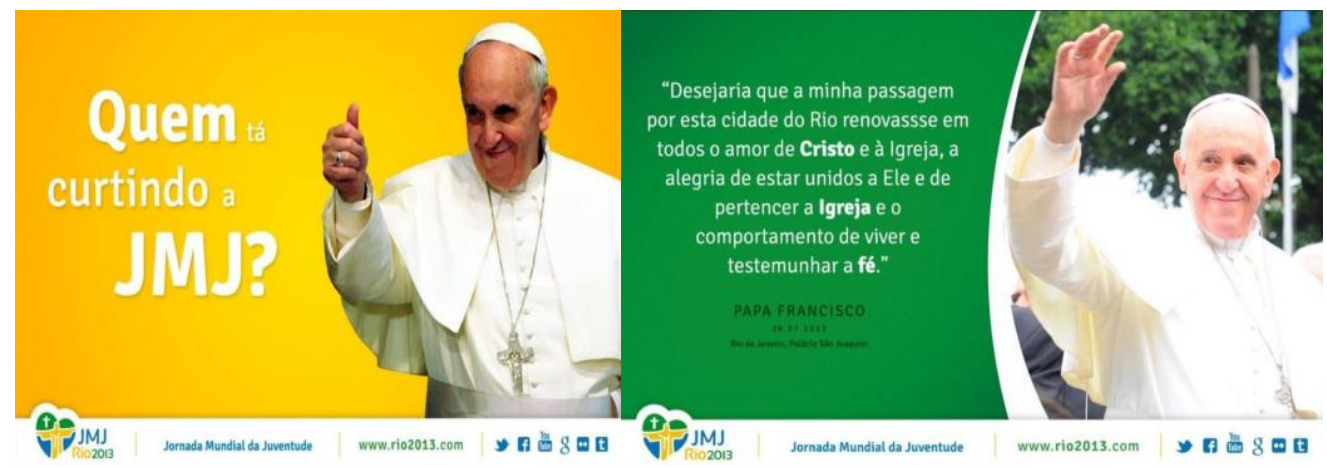

Fonte: www.facebook.com/jornadamundialdajuventude

As duas postagens têm o Papa acenando para alguém fora do quadro. Por meio da composição, podemos inferir que esse "alguém" é o próprio leitor da postagem. As cores amarela e verde são recorrentes na história e no imaginário.

A primeira é uma imagem que comunica rapidamente com a juventude, pois todo o discurso está sedimentado em uma linguagem contemporânea e coloquial. O modo como a frase emerge no quadro faz notar um fragmento atribuído diretamente ao sujeito-Papa, como se ele mesmo se dirigisse à juventude. Também, há três peculiaridades que a torna ainda mais interessante: primeiro o uso do "tá", reformulação popular do verbo "estar" conjugado em terceira pessoa do singular. Ademais, a utilização do verbo curtir no gerúndio, "curtindo" - em vez do verbo "gostar", o mais esperado nesse contexto enunciativo.

É importante frisar que o Facebook possui uma ferramenta que permite ao usuário expressar se gostou ou não de determinada publicação: a opção curtir. Foi daí que o editor da postagem construiu o enunciado, tendo como objetivo gerar "curtidas" para a publicação e a consequente interação na rede social, bem como demonstra a preocupação da Igreja em colocar-se de modo horizontal diante da juventude, falando "para" e "com" ela. Além disso, a interrogativa é uma estratégia que convoca os usuários à participação efetiva nos ambientes virtuais.

A imagem é próxima do leitor e gera uma quebra de expectativa do imaginário do "ser Papa" em uma igreja tão tradicional. Aqui, Francisco sorri com um gesto descontraído, símbolo de "positividade", bem recorrente entre os jovens ocidentais. Esse gesto tem sido retomado intericonicamente por diversos personagens históricos e 


\section{culturae midiätica@}

em memes na internet, postagens de humor, que redesenham personagens tradicionais, normalmente políticos, com essa gestualidade. Ocorre um efeito pré-construído de que a configuração de mão caracterizada pelo dedo polegar voltado para cima e palma fechada indica algo bom ou um agradecimento, o "valeu, galera!” na gíria juvenil. De maneira análoga, o ícone do botão "curtir" no Facebook faz referência ao sinal de positivo do ser humano. Assim, o legal, o bacana, o bom são ressignificados na opção "curtir".

Na segunda postagem, também do dia 26 de julho de 2013, o Papa Francisco acena com um leve sorriso, a iluminação e a edição da foto também contribuem para que se construa um efeito de serenidade. Na memória, encontramos inúmeras imagens nas quais a mão ao céu e o enquadramento contraplongé produzem o efeito de grandiosidade e nobreza, como na fotografia. O corte aproxima o leitor do rosto suavemente sorridente do Papa Francisco, iluminado e perceptível visualmente.

O enunciado verbal retoma um fragmento de um de seus momentos na JMJ, com um discurso de renovação. Esse processo de compartilhamento do mesmo discurso é uma prática comum nos eventos da JMJ, reforçando os enunciados desejáveis e já ditos.

Na memória e no imaginário dos brasileiros, a cor verde comumente expressa a esperança. No enunciado, ela também simboliza equilíbrio. Nesse caso, o discurso do Papa constrói a ideia de uma vida equilibrada por meio do tripé: Cristo, Igreja e fé. A referência interdiscursiva se encontra na denominada virtude teologal da esperança que, segundo a teologia católica, se renova na fé. 


\section{midiätica@ \\ REVISTA DO PROGRAMADE \\ PÓS-GRADUAÇÃO EM COMUNICAÇÃO DA \\ UNIVERSIDADE FEDERAL DA PARAIBAA}

Figuras 6 e 7 - Postagens dos dias 24 e 23 de julho de 2013

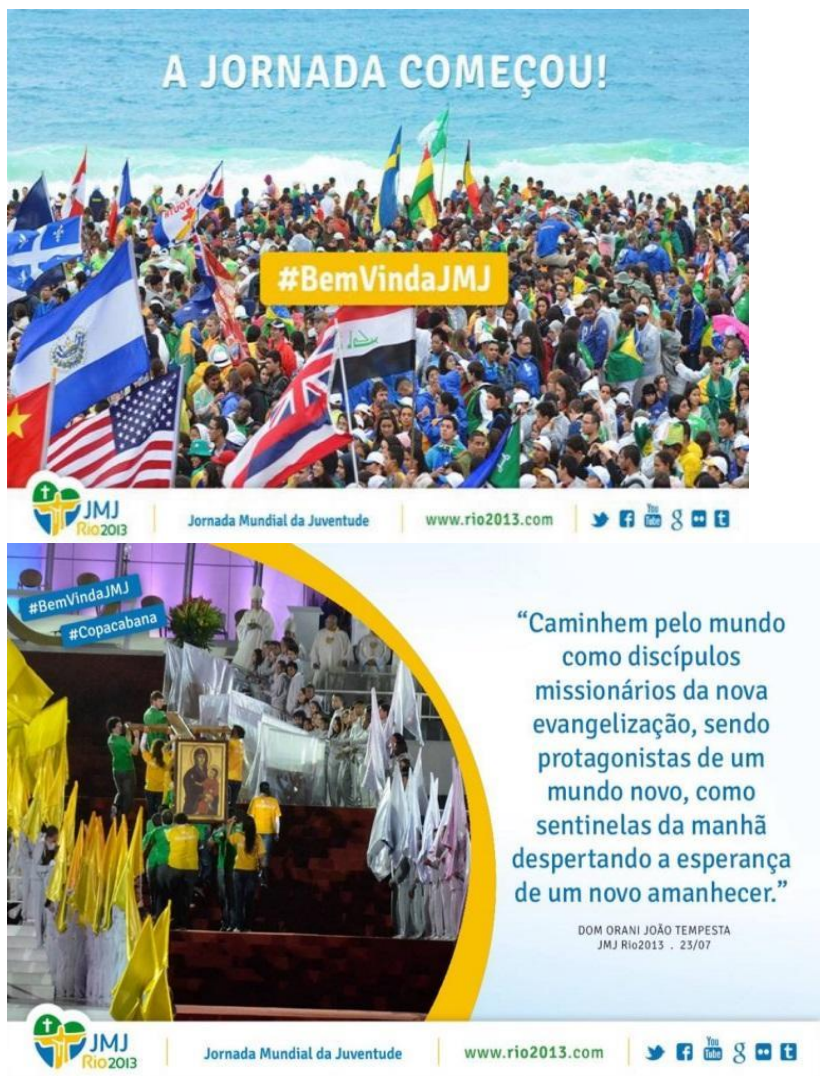

Fonte: www.facebook.com/jornadamundialdajuventude

Nessas duas imagens não é possível identificar os rostos. Os planos gerais mostram apenas fragmentos das inúmeras pessoas que participam da JMJ. Na primeira, se destacam a quantidade de pessoas às margens da praia de Copacabana, as bandeiras de diversos países e a economia das palavras, há apenas dois enunciados. O primeiro é uma afirmação: “A Jornada começou”, acompanhada pela hashtag "\#BemVindaJMJ”, destacada por uma caixa de texto de cor amarela - a mesma tonalidade da figura do “Cristo Redentor", presente no design do evento. Recordamos que o uso das hashtags serve para destacar temas e localizar postagens relacionadas ao mesmo assunto, desde que estejam sinalizadas pelo símbolo “\#” no início da palavra.

O evento tem caráter transnacional, por esse motivo, fez-se necessário demonstrar que lá estavam presentes representantes de muitos países. Essa atitude agrega valor à Jornada, que cumprira com um de seus objetivos: reunir jovens de todas as partes do mundo em um só lugar. Além disso, as bandeiras constroem a discursivização de que a Igreja Católica se comunica com o mundo e a sua mensagem é 


\section{midiäticales}

direcionada a qualquer país, sem fronteiras. Os rostos não são identificados, se constrói, via interdiscurso, a imagem de certa diversidade: a jornada "atrai multidões" de todas as "cores e nacionalidades".

O leitor visualiza a multidão na tela como se estivesse vendo da janela. Não há a aproximação entre ele e a massa de cores e rostos, pouco identificável, em razão do recurso fotográfico do plano geral. Houve manipulação das cores, principalmente na cor azul com o intuito de evidenciar o tom marítimo. Graças à abertura do quadro, mar e céu se encontram imbricados e indissociáveis. Há aqui um efeito intericônico, pois na narrativa bíblica, o céu é uma metáfora para o local da divindade, o "reino de Deus". Assim, a imagem constrói um ambiente idílico, os jovens estariam em um local "abençoado", o "céu" estaria mais próximo naquele ambiente. Os outros elementos gráficos têm um caráter informativo: o selo oficial, a assinatura e o endereço eletrônico do site do evento ("www.rio2013.com").

O segundo post mostra a solenidade da entrega dos símbolos da JMJ, que antecedeu a missa de abertura do evento. Na ocasião, os jovens, ao centro, vestidos com trajes nas cores verde e amarela, levam em procissão um quadro com a pintura de Maria com o menino Jesus nos braços e a "cruz peregrina", que leva esse título por percorrer várias cidades do país-sede durante os meses que antecedem ao evento. Podemos ver o Papa e demais clérigos à espera da procissão. O enunciado é um discurso direto do arcebispo do Rio de Janeiro e cardeal, Dom Orani João Tempesta, e incentiva a missão da juventude na Igreja. Não é possível identificar os jovens que se aproximam do altar, há certo grau de solenidade e distanciamento do leitor em relação às personagens. Por vias da memória, lembramos que a procissão retoma as inúmeras peregrinações religiosas que marcam o catolicismo popular no Brasil (Círio de Nazaré, Aparecida, Juazeiro do Norte etc.).

As cores, mais uma vez, reforçam os sentidos de brasilidade. Mais ainda, a presença do branco formando o caminho de ascensão e a disposição dos peregrinos entre os degraus geram o efeito do caminho celeste, quanto mais se percorre o corredor, mais perto se está do Alto, metáfora do reino celeste. A cor vermelha em tons mais fortes no tapete resgata, por vias intericônicas, o martírio de Jesus, recorrente na liturgia eclesiástica. 


\section{midiäticale}

O texto verbal posicionado ao lado da fotografia traz locuções que incitam o jovem a viver uma nova realidade da Igreja Católica. Os sentidos de "novidade" são reforçados e estimulados no imaginário social. A partir desse contex to sócio histórico, pode-se notar que os excertos "nova evangelização", "mundo novo" e "novo amanhecer" fazem referência a uma nova imagem da Igreja que se personifica nas atitudes e nas mudanças conduzidas pelo Papa Francisco. A reiteração do adjetivo "novo" e a metáfora da sentinela que espera a aurora, ou seja, a "luz que vence as trevas", como enuncia a liturgia da missa, ativam os sentidos de esperança e transformação.

Há uma visão personalista da história. As atitudes simples do líder, amplamente divulgadas pela imprensa, seja abdicar do tradicional sapato vermelho, da cruz de ouro, dos parâmetros "reais", do luxuoso apartamento, são metonímias das transformações da própria instituição.

A hashtag "\#Copacabana" é uma estratégia de marketing conhecida no cotidiano de muitas empresas que usam as redes sociais. No instante em que a hashtag é usada, qualquer pessoa que buscasse essa praia poderia se deparar com a postagem da JMJ, mesmo que o assunto/tema religioso não fosse o foco de interesse.

Figura 8 - Postagem do dia 28 de julho de 2013

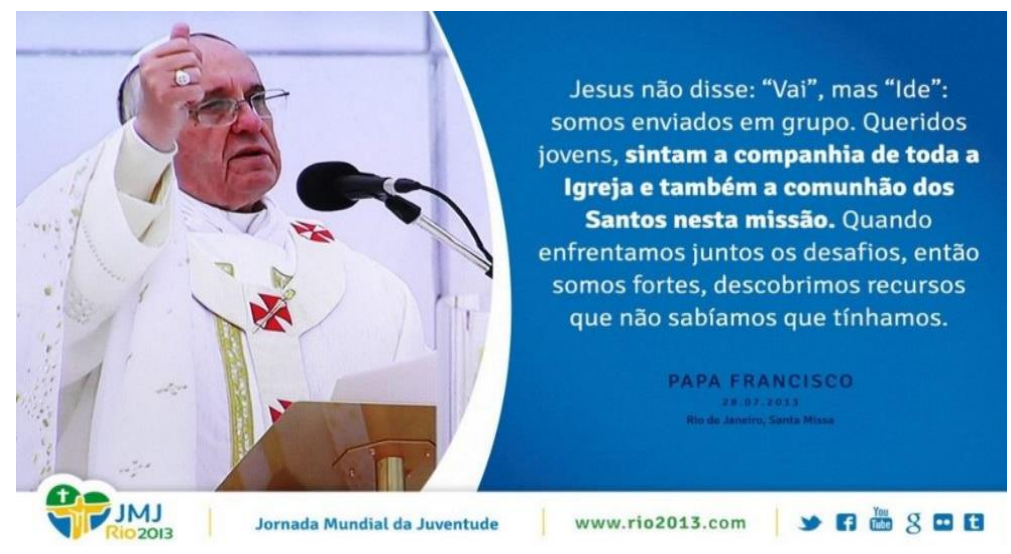

Fonte: www.facebook.com/jornadamundialdajuventude

Das publicações selecionadas, essa é única em que o Papa Francisco foi fotografado com a expressão séria. Se, nas anteriores, abundavam sorrisos; nessa, o pontífice deixa transparecer uma expressão de austeridade. A publicação é datada do domingo, encerramento da jornada, a chamada "missa de envio". Para suavizar, os 


\section{midiäticale}

editores da imagem elegeram uma tonalidade azul que, por vias intericônicas, remete a uma atmosfera celestial.

No enunciado, há um componente importante: o uso do verbo "ser" conjugado na primeira pessoa do plural (“somos enviados em grupo"). Tal enunciado porta o discurso "comunitarista", que defende o ideal de vivência em grupo, de comunidade. Por meio do interdiscurso, recordarmos a circulação da ideologia individualista em uma sociedade "líquido-moderna" (BAUMAN, 2001), que é frontalmente oposta à formação ideológica da Igreja. Aqui se apresenta uma estratégia de denegação: “Jesus não disse: 'vai', mas 'ide'”. Dessa forma, há o convite ao engajamento eclesial, uma vez que o próprio Papa se inclui, o "nós somos”. Integrar-se à Igreja é um imperativo. Para isso, é preciso apelar para força espiritual: "sintam [...] também a comunhão dos santos nesta missão". A metáfora da luta também está presente no discurso: é preciso enfrentar os desafios de maneira coletiva, pois assim "somos mais fortes".

O gestual também é prenhe de sentidos, por vias intericônicas, o punho fechado com o braço erguido à frente é um sinal de “estímulo" e de “ordem”. Dessa forma, se constrói uma imagem de um líder firme e encorajador.

\section{Considerações finais}

O presente texto buscou identificar as estratégias discursivas usadas nas postagens em destaque na página oficial da Jornada Mundial da Juventude no Facebook, no período de 23 a 28 de julho de 2013. Esse seria um período de renovação da Igreja sob a liderança do novo pontífice, recém-empossado, tido como mais próximo ao povo e aos pobres pela grande imprensa.

É preciso considerar que os efeitos de sentido foram produzidos também pela sistematização, periodicidade e reiteração dos posts publicitários no Facebook ao longo daqueles dias. É possível identificar uma prática discursiva que gerou significações de renovação e de proximidade com a juventude.

Embora diferentes, os posts têm em comum o direcionamento para o públicoestratégico: os jovens. Assim, é preciso incentivá-los e atraí-los para gerar novas "vocações" e fortalecer a doutrina católica em um mundo "líquido-moderno", que tende ao individualismo e a uma espiritualidade mais pessoal. 


\section{midiäticale}

As postagens usam os discursos, fotografias e citações do Papa Francisco para seduzir e arrebanhar novas ovelhas para a Igreja. Por isso, identificamos mensagens que enunciavam o novo: liderada pelo Papa Francisco, a Igreja convida a juventude a "agarrar a missão de discípulos", formar um "novo mundo", propagar uma "nova evangelização", e assim construir um "novo amanhã".

Do ponto de vista imagético, há questões recorrentes: o tipo de corte utilizado nas imagens em que o Papa aparece produz efeitos de aproximação com o leitor, ele está sempre em plano médio. Já as imagens da juventude estão em plano geral para gerar o efeito de multidão, metonímia do sucesso do evento. Além disso, as imagens utilizam luzes suaves e brilho que permitem identificar a cena fotografada sem grandes dificuldades. Constrói-se uma estética clean e facilmente visível, que se coaduna com o novo tempo vivido pela Igreja.

Nas camisas, no selo da JMJ e em outros pequenos utensílios, temos a presença do verde-amarelo, metonímia da brasilidade e do nacionalismo. As cores também foram responsáveis por tornar híbridas as mensagens de esperança e de estímulo que o Papa Francisco fez referência nos textos analisados. Houve também manipulação das imagens de modo a engrandecer a mensagem que se desejava passar, tal como aconteceu na manipulação da cor do mar, a fim de atribuir a ele a ideia de céu, e, numa outra publicação, a santidade do Papa realçada por meio da manipulação de exposição da luz. Outro fato percebido é que, quando presentes nos planos de fundo das postagens, as cores agiam implicitamente sobre o leitor/usuário, que ao ler/ver a mensagem, também era influenciado por meio da ação da psicodinâmica causada por elas.

Esta análise exploratória identificou a importância dada à categoria "jovem" por parte da Igreja no Brasil. Desde o pontificado de Karol Wojtyla (João Paulo II), considerado um Papa carismático e peregrino, a instituição clerical tem buscado conquistar a juventude. Não sem razão, em 20 de fevereiro de 2018, foi lançado em seis idiomas o novo livro do Papa, intitulado Deus é jovem.

Destacamos também que as mídias sociais têm ocupado grande parte do tempo do jovem. A interação promovida entre as diferentes mídias tem incentivado experiências jamais vividas por outras gerações. Graças às condutas inovadoras realizadas, a Igreja Católica tem se tornado mais atrativa à juventude, transformando-se, por intermédio do Papa Francisco, na forma de agir e de tratar o fiel católico; 


\section{midiäticales}

comunicando de maneira menos formal, usando a ambiência tecnológica para a doutrinação desse público-estratégico.

Este trabalho identificou as construções discursivas, ancoradas na memória discursiva, operadas pela Igreja para atrair o público jovem. Observamos também o papel da propaganda como estratégia de sedução e de construção de um reposicionamento da instituição e o fortalecimento da imagem institucional.

\section{Referências}

ALMEIDA, R. A visita de Francisco e a abertura do compasso. Estudos de Religião, [s.1.], v. 27, n. 2, p. 297-303, 31 dez. 2013.

ALTHUSSER, Lois. Aparelhos ideológicos do Estado. Lisboa: Presença, 1970.

BAUMAN, Zygmunt. Modernidade líquida. Rio de Janeiro: Zahar, 2001.

BRIGGS, Asa; BURKE, Peter. Uma história da mídia social: de Gutenberg à Internet. 2. ed. Rio de Janeiro: Zahar, 2006.

CASTELLS, Manuel. A sociedade em rede: a era da informação: economia, sociedade e cultura, v. 1. São Paulo: Paz e Terra, 1999.

COURTINE, Jean-Jacques. Discursos sólidos, discursos líquidos: a mutação das discursividades contemporâneas. In: SARGENTINI, Vanice; GREGOLIN, Maria do Rosário. (Org.). Análise do discurso: heranças, métodos e objetos. São Carlos: Claraluz, 2008.

CRUZ, Adriano Charles. A charge no governo Lula: crítica e resistência ao neoliberalismo. Natal: EDUFRN, 2014.

FARINA, Modesto. Psicodinâmica das cores em comunicação. 5. ed. São Paulo: Edgard Blusher, 2000.

G1. Papa Francisco almoça com funcionários do Vaticano. Disponível em: http://g1.globo.com/mundo/noticia/2014/07/papa-francisco-almoca-com-funcionariosdo-vaticano.html>. Acesso em: 20 ago. 2018.

JENKINS, Henry. Cultura da convergência. 2. ed. São Paulo: Aleph, 2009.

HJARVARD, Stig. A midiatização da cultura e da sociedade. São Leopoldo: Unisinos, 2014.

HALL, Stuart. A identidade cultural na pós-modernidade. 12. ed. São Paulo: Saraiva, 2014. 


\section{midiătica@e}

KARTAJAYA, Hermawan; KOTLER, Philip; SETIAWAN, Iwan. Marketing 3.0: as forças que estão definindo o novo marketing centrado no ser humano. Tradução Ana Beatriz Rodrigues. Rio de Janeiro: Elsevier, 2010.

O ESTADO DE S. PAULO. Papa liga para família de jornalista americano morto. Disponível em: <https://internacional.estadao.com.br/noticias/geral,papa-liga-parafamilia-de-jornalista-americano-morto,1547837>. Acesso em: 18 ago. 2018.

ORLANDI, Eni. Análise de discurso: princípios e procedimentos. 7. ed. Campinas: Pontes, 2007.

PÊCHEUX, Michel. Semântica e discurso: uma crítica à afirmação do óbvio. Tradução Eni P. Orlandi. Campinas: Editora da Unicamp, 1997.

PRADO, Elisa Miranda. Imagem e reputação na era da transparência: as boas práticas de comunicação a serviço dos líderes. São Paulo: ABERJE, 2013.

THE TIMES. "Francis effect" pulls crowds back to church. Disponível em: <https://www.thetimes.co.uk/article/francis-effect-pulls-crowds-back-to-churchsb5stbzmzgt>. Acesso em: 10 jul. 2018. 